\title{
A review of phytochemistry, metabolite changes, and medicinal uses of the common food mung bean and its sprouts (Vigna radiata)
}

\author{
Dongyan Tang ${ }^{*}$, Yinmao Dong ${ }^{1,2}$, Hankun Ren², Li Li and Congfen $\mathrm{He}^{2}$
}

\begin{abstract}
The seeds and sprouts of mung bean (Vigna radiata), a common food, contain abundant nutrients with biological activities. This review provides insight into the nutritional value of mung beans and its sprouts, discussing chemical constituents that have been isolated in the past few decades, such as flavonoids, phenolic acids, organic acids, amino acids, carbohydrates, and lipids. Moreover, we also summarize dynamic changes in metabolites during the sprouting process and related biological activities, including antioxidant, antimicrobial, anti-inflammatory, antidiabetic, antihypertensive, lipid metabolism accommodation, antihypertensive, and antitumor effects, etc., with the goal of providing scientific evidence for better application of this commonly used food as a medicine.
\end{abstract}

Keywords: Mung bean, Nutritional value, Chemical constituents, Metabolites, Biological activities

\section{Review}

Introduction

With increasing clinical evidence suggesting that plantderived foods have various potential health benefits, their consumption has been growing at a rate of 5\%-10\% per year [1]. Moreover, many worldwide health organizations have recommended an increase in the intake of plant-derived foods to improve health status and prevent chronic diseases [2].

The mung bean (Vigna radiata) has been consumed as a common food in China for more than 2,000 years. It is well known for its detoxification activities and is used to refresh mentality, alleviate heat stroke, and reduce swelling in the summer. In the book Ben Cao Qiu Zhen (本草求真), the mung bean was recorded to be beneficial in the regulation of gastrointestinal upset and to moisturize the skin [3]. The seeds and sprouts of mung beans are also widely used as a fresh salad vegetable or common food in India, Bangladesh, South East Asia, and western countries [4]. As a food, mung beans contain balanced nutrients, including protein and dietary fiber, and significant amounts of bioactive phytochemicals. High levels of proteins, amino acids,

\footnotetext{
* Correspondence: dongyantang2013@126.com

'Department of Chemistry, Harbin Institute of Technology, Harbin 150000, China

Full list of author information is available at the end of the article
}

oligosaccharides, and polyphenols in mung beans are thought to be the main contributors to the antioxidant, antimicrobial, anti-inflammatory, and antitumor activities of this food and are involved in the regulation of lipid metabolism [5-8].

In recent years, studies have shown that the sprouts of mung beans after germination have more obvious biological activities and more plentiful secondary metabolites since relevant biosynthetic enzymes are activated during the initial stages of germination. Thus, germination is thought to improve the nutritional and medicinal qualities of mung beans [9]. Highly efficient use of mung beans according to evidence demonstrated from scientific experiments will be beneficial to the application of mung beans as a health food, medicine, and cosmetic [10]. In the present review, we summarize the nutritional value, chemical constituents, and metabolite changes during the sprouting process, as well as pharmacological activities, and clinical applications of mung beans, which will provide a better understanding of the potential applications of this common food.

\section{Nutritional value of mung beans as a common food}

Mung beans are a pulse or food legume crop used primarily as dried seeds and occasionally as forage or green pods and seeds for vegetables [11]. Dried seeds may be eaten 
whole or split, cooked, fermented, or milled and ground into flour. Mung beans can also be made into products like soups, porridge, confections, curries, and alcoholic beverages. In western cultures, mung bean sprouts are popularly used as a fresh salad vegetable [12].

Importantly, mung beans are composed of about $20 \%-$ $24 \%$ protein. Globulin and albumin are the main storage proteins found in mung bean seeds and make up over $60 \%$ and $25 \%$ of the total mung bean protein, respectively. Therefore, due to its high protein content and digestibility, consumption of mung beans in combination with cereals can significantly increase the quality of protein in a meal $[13,14]$. Mung bean protein is rich in essential amino acids, such as total aromatic amino acids, leucine, isoleucine, and valine, as compared with the FAO/WHO (1973) reference. However, compared with the reference pattern, mung bean protein is slightly deficient in threonine, total sulfur amino acids, lysine, and tryptophan [15]. Moreover, the proteolytic cleavage of proteins during sprouting leads to a significant increase in the levels of amino acids.

Mung beans have much greater carbohydrate content $(50 \%-60 \%)$ than soybeans, and starch is the predominant carbohydrate in the legume. Due to its high starch content, mung beans have typically been used for the production of starchy noodles, also called muk in Korea. Oligosaccharides, including raffinose, stachyose, and verbascose, in raw or poorly processed legumes are associated with flatulence in the human diet. While these oligosaccharides are present in mung beans, they are soluble in water and can be eliminated by adequate presoaking, germination, or fermentation. The energy offered by mung beans and sprouts is lower than that of other cereals, which is beneficial for individuals with obesity and diabetes [16]. In addition, trypsin inhibitors, hemagglutinin, tannins, and phytic acid found in the mung bean have also been reported to have biological functions, promoting digestion and eliminating toxins [17].

In addition to high protein and low energy content, mung beans also contain various enzymes and plentiful microelements. For example, superoxide dismutase (SOD) extracted from the mung bean can be chemically modified and made into an SOD oral liquid. This chemically modified SOD can avoid destruction by gastric acid and pepsin, thereby extending its half-life, making it suitable for human oral absorption [17].

Overall, regular consumption of mung beans could regulate the flora of enterobacteria, decrease the absorption of toxic substances, reduce the risk of hypercholesterolemia and coronary heart disease, and prevent cancer [18].

\section{Chemical constituents}

During the past few decades, flavonoids, phenolic acids, organic acids and lipids have been identified from the seeds and sprouts of mung beans and have been shown to contribute to its pharmaceutical activities. The structures of these constituents and corresponding plant sources are summarized in Figure 1.

\section{Flavonoids}

Flavone, isoflavone, flavonoids, and isoflavonoids (compounds 1-44 in Table 1) are the important metabolites found in the mung bean [19,20]. Most flavonoids have polyhydroxy substitutions and can be classified as polyphenols with obvious antioxidant activity. Vitexin (apigenin-8-C- $\beta$ glucopyranoside) and isovitexin (apigenin-6-C- $\beta$-glucopyranoside) have been reported to be present in mung bean seeds at about 51.1 and $51.7 \mathrm{mg} \mathrm{g}^{-1}$, respectively [21,22]. Flavonoids are involved in stress protection (i.e., oxidative and temperature stress), early plant development, signaling (i.e., legume nodulation), and protection from insect and mammalian herbivores [23].

\section{Phenolic acids}

Phenolic acids are secondary metabolites primarily synthesized through the pentose phosphate pathway (PPP) and shikimate and phenylpropanoid pathways [6]. Phenolic acids are major bioactive phytochemicals, and their

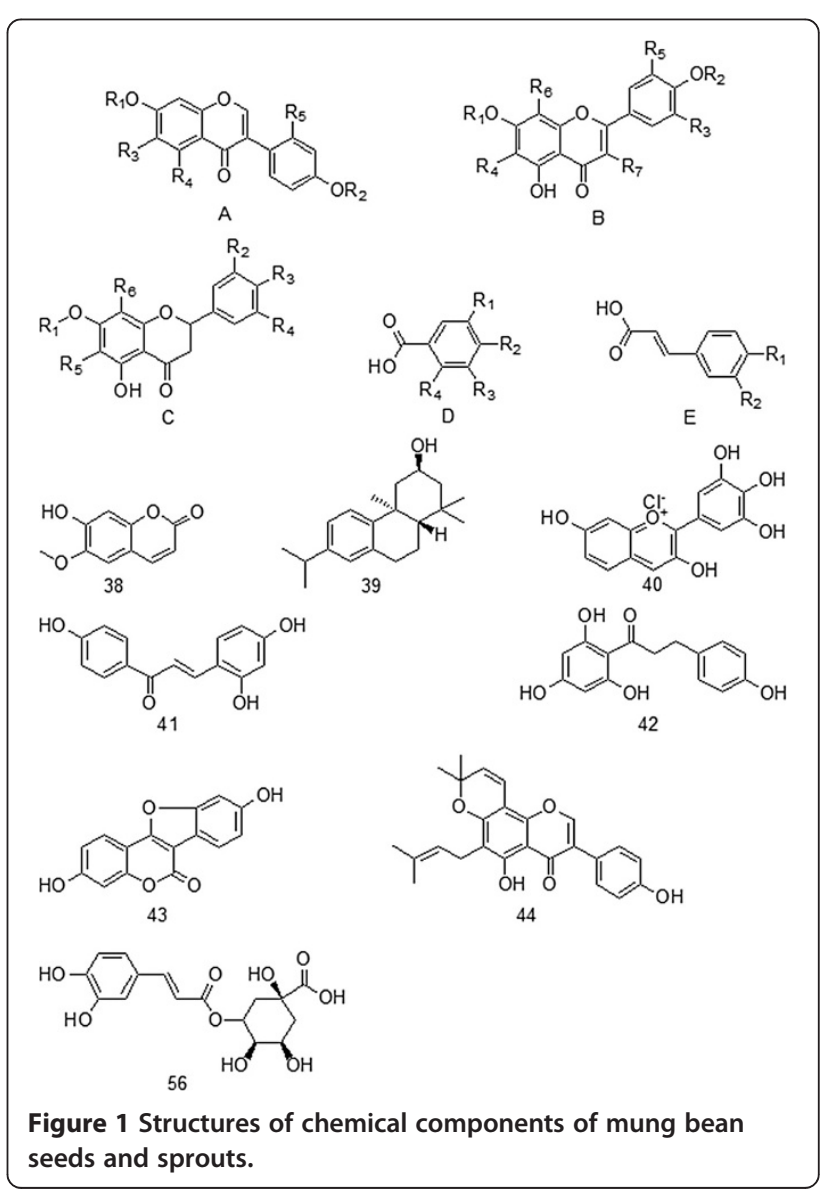


Table 1 Chemical constituents identified from mung bean seeds and sprouts

\begin{tabular}{|c|c|c|c|c|c|c|c|c|c|c|}
\hline \multicolumn{11}{|c|}{ Flavonoids } \\
\hline No. & Compound name & Skeleton & R1 & R2 & R3 & R4 & R5 & R6 & R7 & Ref \\
\hline 1 & Daidzin & $A$ & Glc & $\mathrm{H}$ & $\mathrm{H}$ & $\mathrm{H}$ & $\mathrm{H}$ & - & - & 17 \\
\hline 2 & Daizein & A & $\mathrm{H}$ & $\mathrm{H}$ & $\mathrm{H}$ & $\mathrm{H}$ & $\mathrm{H}$ & - & - & 17 \\
\hline 3 & Ononin & A & Glc & $\mathrm{CH}_{3}$ & $\mathrm{H}$ & $\mathrm{H}$ & $\mathrm{H}$ & - & - & 17 \\
\hline 4 & Formononetin & A & $\mathrm{CH}_{3}$ & $\mathrm{H}$ & $\mathrm{H}$ & $\mathrm{H}$ & $\mathrm{H}$ & - & - & 17 \\
\hline 5 & Isoformononetin & A & $H$ & $\mathrm{CH}_{3}$ & $\mathrm{H}$ & $\mathrm{H}$ & $\mathrm{H}$ & - & - & 17 \\
\hline 6 & $6,7,4^{\prime}$-trihydroxyisoflavone & A & $\mathrm{H}$ & $\mathrm{H}$ & $\mathrm{OH}$ & $\mathrm{H}$ & $\mathrm{H}$ & - & - & 17 \\
\hline 7 & 6,7,4'-trimethoxyisoflavone & A & $\mathrm{CH}_{3}$ & $\mathrm{CH}_{3}$ & $\mathrm{OCH}_{3}$ & $\mathrm{H}$ & $\mathrm{H}$ & - & - & 17 \\
\hline 8 & Genistin & A & Glc & $\mathrm{H}$ & $\mathrm{H}$ & $\mathrm{OH}$ & $\mathrm{H}$ & - & - & 17 \\
\hline 9 & Sissotrin & A & Glc & $\mathrm{CH}_{3}$ & $\mathrm{H}$ & $\mathrm{OH}$ & $\mathrm{H}$ & - & - & 17 \\
\hline 10 & Genistein & A & $H$ & $H$ & $\mathrm{H}$ & $\mathrm{OH}$ & $\mathrm{H}$ & - & - & 17 \\
\hline 11 & Prunetin & A & $\mathrm{CH}_{3}$ & $\mathrm{H}$ & $\mathrm{H}$ & $\mathrm{OH}$ & $\mathrm{H}$ & - & - & 17 \\
\hline 12 & Biochanin A & A & $\mathrm{H}$ & $\mathrm{CH}_{3}$ & $\mathrm{H}$ & $\mathrm{OH}$ & $\mathrm{H}$ & - & - & 17 \\
\hline 13 & 6"-O-acetylgenistin & A & GlcA & $H$ & $\mathrm{H}$ & $\mathrm{OH}$ & $\mathrm{H}$ & - & - & 17 \\
\hline 14 & 5,7,4'-trimethoxyisoflavone & A & $\mathrm{CH}_{3}$ & $\mathrm{CH}_{3}$ & $\mathrm{H}$ & $\mathrm{OCH}_{3}$ & $\mathrm{H}$ & - & - & 17 \\
\hline 15 & 2'-hydroxygenistein & A & $\mathrm{H}$ & $\mathrm{H}$ & $\mathrm{H}$ & $\mathrm{OH}$ & $\mathrm{OH}$ & - & - & 17 \\
\hline 16 & Apigenin & B & $\mathrm{H}$ & $\mathrm{H}$ & $\mathrm{H}$ & $\mathrm{H}$ & $\mathrm{H}$ & $\mathrm{H}$ & $\mathrm{H}$ & 17 \\
\hline 17 & Vitexin & B & $\mathrm{H}$ & $\mathrm{H}$ & $\mathrm{H}$ & $\mathrm{H}$ & $\mathrm{H}$ & Glc & $\mathrm{H}$ & 20,21 \\
\hline 18 & Isovitexin & B & $\mathrm{H}$ & $\mathrm{H}$ & $\mathrm{H}$ & Glc & $\mathrm{H}$ & $\mathrm{H}$ & $\mathrm{H}$ & 20,21 \\
\hline 19 & Rutin & B & $\mathrm{H}$ & $\mathrm{H}$ & $\mathrm{H}$ & $\mathrm{H}$ & $\mathrm{OH}$ & $\mathrm{H}$ & OGlc- $R h a$ & 17 \\
\hline 20 & Quercetin-3-glucoside & B & $\mathrm{H}$ & $\mathrm{H}$ & $\mathrm{OH}$ & $\mathrm{H}$ & $\mathrm{H}$ & $\mathrm{H}$ & OGlc & 17 \\
\hline 21 & Quercetin & B & $\mathrm{H}$ & $\mathrm{H}$ & $\mathrm{OH}$ & $\mathrm{H}$ & $\mathrm{H}$ & $\mathrm{H}$ & $\mathrm{OH}$ & 17 \\
\hline 22 & Kaempferol & B & $\mathrm{H}$ & $\mathrm{H}$ & $\mathrm{H}$ & $\mathrm{H}$ & $\mathrm{H}$ & $\mathrm{H}$ & $\mathrm{OH}$ & 17 \\
\hline 23 & Myricetin & B & $\mathrm{H}$ & $\mathrm{H}$ & $\mathrm{OH}$ & $\mathrm{H}$ & $\mathrm{OH}$ & $\mathrm{H}$ & $\mathrm{OH}$ & 19 \\
\hline 24 & Rhamnetin & B & $\mathrm{CH}_{3}$ & $\mathrm{H}$ & $\mathrm{OH}$ & $\mathrm{H}$ & $\mathrm{H}$ & $\mathrm{H}$ & $\mathrm{OH}$ & 19 \\
\hline 25 & Kaempferitrin & B & Rha & $\mathrm{H}$ & $\mathrm{H}$ & $\mathrm{H}$ & $\mathrm{H}$ & $\mathrm{H}$ & ORha & 19 \\
\hline 26 & Kaempferol-3-rutinoside & B & $\mathrm{H}$ & $\mathrm{H}$ & $\mathrm{H}$ & $\mathrm{H}$ & $\mathrm{H}$ & $\mathrm{H}$ & OGlc ${ }^{-6}$ Rha & 19 \\
\hline 27 & 3,5,7,3', 4'-pentahydroxyflavonol & B & $\mathrm{H}$ & $\mathrm{H}$ & $\mathrm{H}$ & $\mathrm{OH}$ & $\mathrm{OH}$ & $\mathrm{H}$ & $\mathrm{OH}$ & 19 \\
\hline 28 & $3,7,8,3^{\prime}, 4^{\prime}$-pentahydroxyflavonol & B & $\mathrm{H}$ & $\mathrm{H}$ & $\mathrm{H}$ & $\mathrm{H}$ & $\mathrm{OH}$ & $\mathrm{OH}$ & $\mathrm{OH}$ & 19 \\
\hline 29 & Naringenin-7-glucoside & C & Glc & $\mathrm{H}$ & $\mathrm{OH}$ & $\mathrm{H}$ & $\mathrm{H}$ & $\mathrm{H}$ & - & 17 \\
\hline 30 & Naringin & C & Glc $c^{2} R h a$ & $\mathrm{H}$ & $\mathrm{OH}$ & $\mathrm{H}$ & $\mathrm{H}$ & $\mathrm{H}$ & - & 17 \\
\hline 31 & Neohesperidin & C & Glc ${ }^{2} \mathrm{Rh} a$ & $\mathrm{H}$ & $\mathrm{OCH}_{3}$ & $\mathrm{OH}$ & $\mathrm{H}$ & $\mathrm{H}$ & - & 18 \\
\hline 32 & Hesperetin & C & $\mathrm{H}$ & $\mathrm{OH}$ & $\mathrm{OCH}_{3}$ & OGle & $\mathrm{H}$ & $\mathrm{H}$ & - & 18 \\
\hline 33 & 5,7-dihydroxyflavanone & C & $\mathrm{H}$ & $\mathrm{H}$ & $\mathrm{H}$ & $\mathrm{H}$ & $\mathrm{H}$ & $\mathrm{H}$ & - & 19 \\
\hline 34 & Eriodictyol-7-glucoside & C & Glc & $\mathrm{H}$ & $\mathrm{OH}$ & $\mathrm{OH}$ & $\mathrm{H}$ & $\mathrm{H}$ & - & 19 \\
\hline 35 & Eriodictyol & C & $\mathrm{H}$ & $\mathrm{OH}$ & $\mathrm{OH}$ & $\mathrm{H}$ & $\mathrm{H}$ & $\mathrm{H}$ & - & 19 \\
\hline 36 & Naringenin & C & $\mathrm{H}$ & $\mathrm{H}$ & $\mathrm{OH}$ & $\mathrm{H}$ & $\mathrm{H}$ & $\mathrm{H}$ & - & 18 \\
\hline 37 & Rhododendrin & C & $\mathrm{H}$ & $\mathrm{H}$ & $\mathrm{OH}$ & $\mathrm{H}$ & $\mathrm{CH}_{3}$ & $\mathrm{CH}_{3}$ & - & 19 \\
\hline 38 & Scopoletin & 17 & & & & & & & & \\
\hline 39 & Pomiferin & 17 & & & & & & & & \\
\hline 40 & Delphinidin & 17 & & & & & & & & \\
\hline 41 & 2',4,4'-trihydroxychalcone & 17 & & & & & & & & \\
\hline 42 & phloretin & 17 & & & & & & & & \\
\hline
\end{tabular}


Table 1 Chemical constituents identified from mung bean seeds and sprouts (Continued)

\begin{tabular}{|c|c|c|c|c|c|c|c|c|c|c|}
\hline 43 & coumestrol & 17 & & & & & & & & \\
\hline 44 & osajin & 17 & & & & & & & & \\
\hline \multicolumn{11}{|c|}{ Phenolic acids } \\
\hline 45 & p-hydroxybenzoic & D & $\mathrm{H}$ & $\mathrm{OH}$ & $\mathrm{H}$ & $\mathrm{H}$ & - & - & - & 25 \\
\hline 46 & Protocatechuic & D & $\mathrm{H}$ & $\mathrm{OH}$ & $\mathrm{OH}$ & $\mathrm{H}$ & - & - & - & 25 \\
\hline 47 & Syringic & $\mathrm{D}$ & $\mathrm{OCH}_{3}$ & $\mathrm{OH}$ & $\mathrm{OCH}_{3}$ & $\mathrm{H}$ & - & - & - & 25 \\
\hline 48 & Gallic acid & D & $\mathrm{OH}$ & $\mathrm{OH}$ & $\mathrm{OH}$ & $\mathrm{H}$ & - & - & - & 25 \\
\hline 49 & Vanillic acid & $\mathrm{D}$ & $H$ & $\mathrm{OH}$ & $\mathrm{OCH}_{3}$ & $\mathrm{H}$ & - & - & - & 26 \\
\hline 50 & Gentisic acid & D & $\mathrm{OH}$ & $\mathrm{H}$ & $\mathrm{H}$ & $\mathrm{OH}$ & - & - & - & 26 \\
\hline 51 & Shikimic acid & $\mathrm{D}$ & $\mathrm{OH}$ & $\mathrm{OH}$ & $\mathrm{OH}$ & $\mathrm{H}$ & - & - & - & 26 \\
\hline 52 & $p$-coumaric & E & $\mathrm{OH}$ & $\mathrm{H}$ & - & - & - & - & - & 26 \\
\hline 53 & Cinnamic acid & $E$ & $\mathrm{H}$ & $\mathrm{H}$ & - & - & - & - & - & 26 \\
\hline 54 & Caffeic acid & $\mathrm{E}$ & $\mathrm{OH}$ & $\mathrm{OH}$ & - & - & - & - & - & 26 \\
\hline 55 & Ferulic & $E$ & $\mathrm{OH}$ & $\mathrm{OCH}_{3}$ & - & - & - & - & - & 25 \\
\hline 56 & Chlorogenic acid & & & & & & & & & 25 \\
\hline
\end{tabular}

presence in wild plants has facilitated the trend toward the increasing use of wild plants as foods [24,25].

Twelve phenolic acids (compounds 45-56 in Table 1) have been identified from mung bean seeds and sprouts $[26,27]$. Based on high levels of total phenolics and total flavonoids, mung beans show the benefits of 1,1-diphenyl-2-picrylhydrazyl (DPPH) radical scavenging activities, tyrosinase inhibition, and antiproliferative and alcohol dehydrogenase activities, which allow it to be used as a substitution for proper prescription drugs and as a preventative or therapeutic agent for the treatment of human diseases [28].

\section{Others}

Organic acids and lipids have also been found in mung beans and sprouts. Twenty-one organic acids, including phosphoric and citric acid, and 16 lipids, including $\gamma$ tocopherol, were reported to be the major components of mung beans by gas chromatography/mass spectrometry (GC/MS) [29].

\section{Dynamic changes in metabolites}

Under biotic and abiotic stress, plant physiology dramatically changes. The induction of defense systems, such as those involving proteinase inhibitors, produces a response that protects the plant from these types of stresses [30]. As a part of this response, accumulation of secondary metabolites with various health benefits has been observed [29,31]. However, in the absence of stress, healthy plants can also be stimulated by stress inducers to artificially produce secondary metabolites. Targeted analyses have demonstrated that the germination of mung beans is accompanied by a spectrum of significant changes in metabolite contents, such as decreased antinutrient concentrations [32] and increased levels of free amino acids [15,32-35].

Germination significantly reduces the levels of reducing sugars and starches by $36.1 \%$ and $8.78 \%$, respectively [15]. Interestingly, until $60 \mathrm{~h}$ of incubation, levels of the monosaccharides fructose and glucose increase dramatically in the germinating material. However, significant reductions in the levels of both sugars have been observed during the final germination stage from 60 to $75 \mathrm{~h}$. The concentration of the disaccharide sucrose increases within the first $24 \mathrm{~h}$, but rapidly declines after the initial germination phase $[9,15,29]$. Moreover, raffinose and stachyose are completely eliminated during germination. The decline of sucrose in the latter stages of sprouting may be due to the lack of raffinose, resulting in the hydrolysis of sucrose for the energy supply [15].

Compared to cereals, mung beans contain higher amounts of protein [35]. As described earlier, proteolytic cleavage of proteins during sprouting leads to a significant increase in the levels of most amino acids. Additionally, increased levels of free amino acids in germinated mung beans and lentils have been observed via targeted analysis [33,36].

Gentistic acid, cinnamic acid, and $p$-hydroxybenzoic acid are the major phenolic acids of metabolites that are found throughout the sprouting process [37]. Within the first day of incubation, the levels of caffeic acid, ferulic acid, and shikimic acid are relatively low in mung bean seeds. However, after the initial soaking and early germination phase, mung bean samples exhibit significantly increasing amounts of these compounds [25]. Moreover, the levels of gallic acid, chlorogenic acid, and coumarin increase dramatically in the germination material until day 3 or 4 , and catechin levels increase during the final stage 
of mung bean sprout development (i.e., on the eighth day of incubation) [26].

The overall levels of organic acids also increase during sprouting. Phosphoric and citric acid are 2 of the major organic acid metabolites. A distinct and continuous increase in lactic acid is observed, while malic acid and citric acid peak after only $24 \mathrm{~h}$ of incubation [29].

Fatty acid methyl esters (FAMEs) are formed mainly from transesterification of the crude lipid extract and reflect the presence of mung bean triglycerides. Within the first $24 \mathrm{~h}$ of incubation, changes in the levels of most FAMEs are relatively minimal. However, after the initial soaking and early germination phase, mung bean samples exhibit significant decreases in the levels of FAMEs. In contrast, the levels of $\gamma$-aminobutyric acid in mung bean sprouts are enhanced throughout sprout development and may be of special interest for human nutrition because of its health-promoting effects [29,38].

Protease inhibitors are proteins or peptides capable of inhibiting catalytic activities of proteolytic enzymes that play essential roles in biological systems, regulating proteolytic processes, and participate in defense mechanisms against a large number of insects, fungi, and other pathogenic microorganisms [39]. During the first 5 days of germination, there is a gradual decrease in the levels of extractable trypsin inhibitors in mung bean seeds [40]. The hemagglutinin activity of mung bean seeds has also been reported to decrease by about $84.4 \%$ after 3 days of germination [41].

\section{Biological activities}

In ancient books, mung beans were well known for their detoxification activities. Mung bean protein, tannin, and other polyphenols are thought to combine with organophosphorus pesticides, mercury, arsenic, and other heavy metals, promoting the excretion of sediments from the body [42]. Mung beans have been shown to possess antioxidant, antimicrobial, and anti-inflammatory activities. Moreover, mung beans have antidiabetic, antihypertensive, lipid metabolism accommodation, antihypertensive, and antitumor effects, among others (Table 2). These various properties of this functional legume are discussed below.

\section{Antioxidant effects}

The proteins, polypeptides, polysaccharides, and polyphenols from the seeds, sprouts, and hulls of mung beans all show potential antioxidant activity. The antioxidant capacities of mung bean protein hydrolysate (MPH) have been reported as 0.67 and $0.46 \mu \mathrm{mol}$ Trolox equivalent $(\mathrm{TE}) / \mathrm{mg}$ protein, as measured by oxygen radical absorbance capacity-fluorescein $\left(\mathrm{ORAC}_{\mathrm{FL}}\right)$ and Trolox equivalent antioxidant capacity (TEAC) assays, respectively. Freeze-drying in lactose excipient reduces
Table 2 Biological activities and compounds of mung beans

\begin{tabular}{ll}
\hline Biological activities & Biological compounds \\
\hline Antioxidant effects & $\begin{array}{l}\text { Proteins, polypeptides, } \\
\text { polysaccharides, polyphenols } \\
\text { Antimicrobial activity }\end{array}$ \\
Anti-inflammatory activity & Polyphenols \\
Antidiabetic effects & Polyphenols \\
Lipid metabolism accommodation & Phytosterol \\
Antihypertensive effects & Proteins, amino acids \\
Antitumor effects & Polyphenols, mung bean \\
& trypsin inhibitor fragments \\
Antisepsis effects & Polyphenols, aqueous extracts \\
& from mung bean coat \\
\hline
\end{tabular}

the antioxidant capacity of MPH to $0.48 \mu \mathrm{mol} \mathrm{TE} / \mathrm{mg}$ protein in the ORAC $\mathrm{FL}_{\mathrm{FL}}$ assay, but does not alter the results of the TEAC assay [43].

MP1 and MP2, isolated from the water extract of mung beans, are 2 acid heteropolysaccharides with $9.9 \%$ and $36.4 \%$ uronic acid content, respectively. The main composition of MP1 (molecular weight: $83 \mathrm{kDa}$ ) is mannose, whereas MP2 (molecular weight: $45 \mathrm{kDa}$ ) consists of rhamnose and galactose. MP2 exhibits higher hydroxyl radical-scavenging activity, while MP1 has higher reducing power and stronger scavenging capacity for superoxide and DPPH radicals, as well as greater inhibition of the self-oxidation of 1,2,3-phentriol than MP2 [44].

Importantly, mung bean extracts possess significantly higher radical scavenging activities, greater reducing power, and higher levels of polyphenols than soy bean extracts, suggesting that they are superior functional foods. Indeed, the radical scavenging activities of DPPH and 2,2'-azino-di-(3-ethyl-2,3-dihydrobenzthiazoline -6sulfonate) (ABTS) isolated from mung bean extracts were found to be $11.33 \pm 0.24$ and $36.65 \pm 0.63 \mu \mathrm{mol} / \mathrm{g}$, respectively, and the ferric reducing antioxidant power (FRAP) of mung bean extracts was $31.85 \pm 3.03 \mu \mathrm{mol} / \mathrm{g}$. Mung bean extracts reduce the rate of pyrogallol autoxidation by $85 \%$ compared to the control and possess SOD-like activity of $83.48 \% \pm 0.88 \%$ [ 45$]$.

During the sprouting process, sprout extracts show higher amounts of total phenolics, total flavonoids, and DPPH radical scavenging activity than seed extracts [28]. Additionally, the antioxidant activity of mung bean sprouts is the highest on day 1 or 2 , depending on the analysis method used (i.e., $\beta$-carotene assay or DPPH assay, respectively) [6].

The DPPH scavenging activity (SA) of mung bean soup (MBS; $20 \mathrm{mg} / \mathrm{mL}$ ) is approximately $145 \%$ that of tea soup $(5 \mathrm{mg} / \mathrm{mL}$ ) and $195 \%$ that of vitamin C solution $(0.15 \mathrm{mg} / \mathrm{mL})$, indicating that the DPPH-SA of $100 \mathrm{~g}$ mung bean is equivalent to that of $36.3 \mathrm{~g}$ dried green tea 
and $1462 \mathrm{mg}$ vitamin C. Vitexin and isovitexin are the major antioxidant components in mung beans [46]. Vitexin inhibits DPPH radicals by approximately $60 \%$ at $100 \mu \mathrm{g} / \mathrm{mL}$ and effectively prevents UV-induced skin cell death [47].

\section{Antimicrobial activity}

The use of phytochemicals as natural antimicrobial agents, commonly called 'biocides' is gaining popularity. Enzymes, peptides, and polyphenols extracted from mung beans have been shown to possess both antimicrobial and antifungal activities. Assays for antifungal activity are usually executed using the method of inhibition crescents, while assays for antimicrobial activity are performed using the deferred plate method or the agardiffusion method $[48,49]$.

A nonspecific lipid transfer peptide (nsLTP; molecular weight: $9.03 \mathrm{kDa}$ ) with antimicrobial and antifungal activity was isolated from mung bean seeds. Interestingly, nsLTP exerts antifungal effects on Fusarium solani, F. oxysporum, Pythium aphanidermatum, and Sclerotium rolfsii and antibacterial effects on Staphylococcus aureus but not Salmonella typhimurium [50].

Mungin, a novel cyclophilin-like antifungal protein isolated from mung bean seeds, possesses activity against the fungi Rhizoctonia solani, Coprinus comatus, Mycosphaerella arachidicola, Botrytis cinerea, and F. oxysporum. Mungin also exerts inhibitory activity against $\alpha$ - and $\beta$-glucosidases, suppressing $\left[{ }^{3} \mathrm{H}\right]$ thymidine in corporation by mouse splenocytes [51].

In 2005 , a chitinase $(30.8 \mathrm{kDa})$ with antifungal activity was isolated from mung bean seeds. The protein has a pI of 6.3, as determined by isoelectric focusing, and an estimated specific activity of $3.81 \mathrm{U} / \mathrm{mg}$. The enzyme exhibits optimal activity at $\mathrm{pH} 5.4$ and is stable from 40 to $50^{\circ} \mathrm{C}$. Importantly, chitinase exerts antifungal activity on $R$. solani, F. oxysporum, $M$. arachidicola, P. aphanidermatum, and S. rolfsii [52].

In addition to the above antimicrobial and antifungal effects, polyphenol extracts from mung bean sprouts have also been shown to have activity against Helicobacter pylori, one of the most common bacterial infections in human beings causing gastroduodenal disease [6].

\section{Anti-inflammatory activity}

In Asia, mung beans have been used in various cuisines and in folk remedies to treat toxic poisoning, heat stroke associated with thirst, irritability, and fever; these beneficial effects of mung beans are thought to be related to the inflammatory response [53].

Researchers have analyzed the anti-inflammatory effects of mung bean ethanol extracts on lipopolysaccharide (LPS)-stimulated macrophages. The extract mainly included polyphenols, gallic acid, vitexin, and isovitexin and markedly reduced the activity of murine macrophages through the prevention of pro-inflammatory gene expression without cytotoxicity [54]. Moreover, a study demonstrated that all pro-inflammatory cytokines, including interleukin (IL)- $1 \beta$, IL-6, IL-12 $\beta$, tumor necrosis factor (TNF)- $\alpha$, and inducible NO synthase (iNOS), were dramatically down regulated in cells treated with $3.7 \mathrm{mg} / \mathrm{mL}$ polyphenols. These results suggested that the ethanol extract had great potential to improve the clinical symptoms of inflammation-associated diseases, such as allergies and diabetes [55].

The immune modulatory activities of mung bean water extracts and monomers on human peripheral blood mononuclear cells (PBMCs) have also been evaluated by BrdU immunoassay, secretion of interferon-gamma (IFN- $\gamma$ ) and IL-10, and elucidation of the responding cells by flow cytometry. The results demonstrated that 20 $\mu \mathrm{g} / \mathrm{mL}$ genistein, phytic acid, and syringic acid induce a Th1-predominant immune response through significant suppression of IL-10 secretion and promotion of IFN- $\gamma$ secretion. The study concluded that several nonnutritional ingredients of mung beans, such as flavonoids, acids, and plant hormones, are most likely to be important in the modulation of human immunity [56].

\section{Antidiabetic effects}

Studies have also investigated the antidiabetic effects of mung bean extracts. In a study conducted in 2008, the antidiabetic effects of mung bean sprout extracts and mung bean seed coat extracts were investigated in type 2 diabetic mice (male $\mathrm{KK}-\mathrm{A}^{\mathrm{y}}$ mice and $\mathrm{C} 57 \mathrm{BL} / 6$ mice). These extracts were orally administered to $\mathrm{KK}-\mathrm{A}^{\mathrm{y}}$ mice for 5 weeks, and mung bean sprout extracts $(2 \mathrm{~g} / \mathrm{kg})$ and mung bean seed coat extracts $(3 \mathrm{~g} / \mathrm{kg}$ ) lowered blood glucose, plasma C-peptide, glucagon, total cholesterol, triglycerides, and blood urea nitrogen (BUN) levels. At the same time, both treatments markedly improved glucose tolerance and increased insulin immunoreactive levels [57].

Phenolic antioxidants and levo-dihydroxy phenylalanine (L-DOPA) can be enriched in mung bean extracts through solid-state bioconversion (SSB) by $R$. oligosporus, with the goal of enhancing health-linked functionality. $\alpha$-Amylase is responsible for cleaving starch during the digestive process, which is important in the management of postprandial blood glucose levels. A study in 2007 by Randir and Shetty investigated the inhibition of $\alpha$-amylase and $H$. pylori in bioprocessed extracts and linked these effects to diabetes management and peptic ulcer management, respectively. The $\alpha$-amylase inhibition potential of the tested sprouts extract was moderately high during early stages (days 0-2) and was higher during days 4-10, which correlated with higher phenolic content [58]. 


\section{Lipid metabolism accommodation}

The modulation of lipid metabolism by mung bean has been well established. In an early study, rabbits with hyperlipidemia were fed a $70 \%$ mixture of mung bean meal and mung bean sprout powder. The mixtures affected the total cholesterol and $\beta$-lipoprotein content, alleviating symptoms of coronary artery diseases [59]. Additionally, in more recent studies, normal mice and rats were fed mung bean extracts for 7 days, and total cholesterol was significantly decreased in both types of rodents. This effect was thought to arise from the phytosterol content of mung beans, which was similar to blood cholesterol, facilitating the prevention of cholesterol biosynthesis and absorption [60].

\section{Antihypertensive effects}

High doses (600 mg peptide/kg body weight) of raw sprout extracts, dried sprout extracts, and enzymedigested sprout extracts have been shown to significantly reduce systolic blood pressure (SBP) in rats after administration for 6-9, 3-6, or 3-9 h, respectively. Similar changes were found in the plasma angiotensin Iconverting enzyme (ACE) activity of these mung bean extracts. A long-term (1-month) intervention study that included treatment with fresh sprout powder, dried sprout powder, and concentrated extracts of the sprouts was carried out. The results indicated that the sprout powders were not as efficacious as concentrated sprout extracts. The SBPs of rats treated with concentrated extracts of fresh and dried sprouts were significantly reduced during the intervention period from weeks 1-4 and weeks $2-4$, respectively [61].

\section{Antitumor effects}

Mung beans have been shown to exert antitumor effects through several different mechanisms. The recombinant plant nucleases R-TBN1 and R-HBN1, similar to nucleases derived from pine pollen and mung beans, were found to be effective against melanoma tumors and were about 10-times more potent than bovine seminal ribonuclease (RNase). Due to their relatively low cytotoxicity and high efficiency, these recombinant plant nucleases appear to be stable biochemical agents that can be targeted as potential antitumor cytostatics [62].

In addition, mung beans have been shown to exert antiproliferative effects, as examined by MTT [3-(4, 5-dimethylthiazol-2-yl)-2,5-diphenyltetrazolium bromide] assay using an in vitro cell culture system. Mung beans exhibit dose-dependent antiproliferative effects against the tongue squamous cell carcinoma cell line CAL27 and several other cancer cell lines tested (i.e., DU145, SK-OV-3, MCF-7, and HL-60 cells) [63].

Another study evaluated the effects of trypsin inhibitors from mung beans (i.e., LysGP33) on the metastasis and proliferation of human colon cancer cells (SW480 cells). In this study, the effects of the purified GSTLysGP33 active fragment on the migration of SW480 cells were detected using wound healing assays. The results showed that $10 \mu \mathrm{mol} / \mathrm{L}$ GST-LysGP33 active fragment affected cell migration beginning at the 24-h time point. After $72 \mathrm{~h}$, cells treated with GST-LysGP33 exhibited an approximate 50\% reduction in wound healing compared to the control group [64].

\section{Antisepsis effects}

The aqueous extract from mung bean coat (MBC) is protective against sepsis in vitro and in vivo. The effect was achieved by the inhibition of high mobility group box 1 (HMGB1), a nucleosomal protein that has recently been established as a late mediator of lethal systemic inflammation with a relatively wider therapeutic window for pharmacological interventions. It was found that $\mathrm{MBC}$ dose-dependently attenuated the LPS-induced release of HMGB1 and several chemokines in macrophage cultures. The animal survival rates after oral administration of MBC were significantly increased from $29.4 \%$ (in the saline group, $\mathrm{N}=17$ mice) to $70 \%$ (in the experimental MBC extract group, $\mathrm{N}=17$ mice, $P<0.05)$ [65]. Chlorogenic acid (56) has also been shown to be protective against lethal sepsis by inhibiting late mediators of sepsis. Chlorogenic acid suppresses endotoxin-induced HMGB1 release in a concentration-dependent manner in murine peritoneal macrophages. Additionally, administrations of chlorogenic acid attenuate systemic HMGB1 accumulation in vivo and prevented mortality induced by endotoxemia and polymicrobial sepsis [66].

\section{Conclusion}

The mung bean [Vigna radiata (L.) Wilczek] is one of the most important short-season, summer-growing legumes and is grown widely throughout tropic and subtropic regions. As we have discussed in this review, mung beans have wide applications in agriculture, health food, pharmaceutical, and cosmetics industries. Mung bean seeds and sprouts are excellent examples of functional foods that lower the risk of various diseases. Moreover, the seeds and sprouts have health-promoting effects in addition to their nutritive value.

During the germination process of the mung bean, its chemical constituents undergo a series of biochemical reactions. One such reaction is the synthesis of small active compounds from macromolecular substances, promoting absorption and utilization. Another change observed during germination is the formation and accumulation of many types of active substances, such as polyphenols, saponins, vitamin $\mathrm{C}$, etc. Therefore, we believes that these changes in the chemical composition of mung beans during germination will lead to substantial 
and important changes in the pharmacological activities of mung beans as well.

Research into the chemical constituents and biological activities of mung bean seeds and sprouts have provided a solid theoretical basis for the development and utilization of mung beans. Combined with analysis of the metabolites of these chemical constituents, research investigating the physiological functions of these compounds is required for further advancement of this field. Thus, future studies may focus on the extraction and purification of new physiologically active substances in agriculture, health foods, cosmetics, and pharmaceutical applications.

\section{Abbreviations}

FAO/WHO: Food and Agriculture Organization/World Health Organization; SOD: Superoxide dismutase; PPP: Pentose phosphate pathway; DPPH: 1, 1-Diphenyl-2-picrylhydrazyl; GC/MS: Gas chromatography/mass spectrometry; FAMEs: Fatty acid methyl esters; MPH: Mung bean protein hydrolysate; TE: Trolox equivalent; ORAC FL: Oxygen radical absorbance capacityfluorescein; TEAC: Trolox equivalent antioxidant capacity; ABTS: 2,2'-Azino-di(3-ethyl-2,3-dihydrobenzthiazoline -6-sulfonate); FRAP: Ferric reducing antioxidant power; SA: Scavenging activity; MBS: Mung bean soup; nsLTP: Nonspecific lipid transfer peptide; LPS: Lipopolysaccharide; IL: Interleukin; TNF: Tumor necrosis factor; PBMCs: Peripheral blood mononuclear cells; IFN- : Interferon-gamma; BUN: Blood urea nitrogen; L-DOPA: Levo-dihydroxy phenylalanine; SSB: Solid-state bioconversion; SBP: Systolic blood pressure; ACE: Angiotensin l-converting enzyme; RNase: Ribonuclease; MTT: [3-(4,5-dimethylthiazol-2-yl)-2,5diphenyltetrazolium bromide]; MBC: Mung bean coat; HMGB1: High mobility group box 1.

\section{Competing interests}

The authors declare that they have no competing interests.

\section{Authors' contributions}

DY, LL, and $\mathrm{RH}$ were involved in preparing the manuscript. TD and $\mathrm{HC}$ participated in discussions of views represented in the paper. All authors have read and approved the final manuscript.

\section{Acknowledgements}

This work was supported by the Research Foundation for Youth Scholars of Beijing Technology and Business University (QNJJ2012-27).

\section{Author details}

'Department of Chemistry, Harbin Institute of Technology, Harbin 150000, China. ${ }^{2}$ Beijing Key Lab of Plant Resources Research and Development, Beijing Technology and Business University, Beijing 100048, China.

Received: 10 July 2013 Accepted: 2 January 2014

Published: 17 January 2014

\section{References}

1. Tham DM, Gardner CD, Haskell WL: Potential health benefits of dietary phytoestrogens: a review of the clinical, epidemiological, and mechanistic evidence. J Clinical Endocrinology \& Metabolism 1998, 83(7):2223-2235.

2. Espin JC, Garcia-Conesa MT, Tomas-Barberan FA: Nutraceuticals: facts and fiction. Phytochemistry 2007, 68:2986-3008.

3. Min L: Research advance in chemical composion and pharmacological action of mung bean. Shanghai J Trad Chin Med 2001, 5:18.

4. Fery RL: The cowpea: production, utilization, and research in the United States. Horticultural Reviews 1990, 12:197-222.

5. Kanatt SR, Arjun K, Sharma A: Antioxidant and antimicrobial activity of legume hulls. Food Res Int 2011, 44:3182-3187.
6. Randhir R, Lin Y-T, Shetty K: Stimulation of phenolics, antioxidant and antimicrobial activities in dark germinated mung bean sprouts in response to peptide and phytochemical elicitors. Process Biochem 2004, 39:637-646.

7. Vanamala J, Reddivari L, Yoo KS, Pike LM, Patil BS: Variation in the content of bioactive flavonoids in different brands of orange and grapefruit juices. J Food Comp Anal 2006, 19:157-166.

8. Anjum NA, Umar S, lqbal M, Khan NA: Cadmium causes oxidative stress in mung bean by affecting the antioxidant enzyme system and ascorbateglutathione cycle metabolism. Russian J Plant Physiol 2011, 58:92-99.

9. El-Adawy T, Rahma E, El-Bedawey A, El-Beltagy A: Nutritional potential and functional properties of germinated mung bean, pea and lentil seeds. Plant Foods Hum Nutr 2003, 58:1-13.

10. Golob P: The use of spices and medicinals as bioactive protectants for grains. Rome: FAO Agricultural Sciences Bulletin No. 137; 1999.

11. Tomooka N: Two new species, new species combinations and sectional designations in Vigna subgenus Ceratotropis (Piper) Verdcourt (Leguminosae, Phaseoleae). Kew Bull 2002, 57:613-624.

12. Lambrides CJGI: Mungbean. Gen Mapp Mol Breed Plants 2007, 3:69-90.

13. Wang SY, Wu JH, Ng TB, Ye XY, Rao PF: A non-specific lipid transfer protein with antifungal and antibacterial activities from the mung bean. Peptides 2004, 25:1235-1242.

14. Kudre TG, Benjakul S, Kishimura H: Comparative study on chemical compositions and properties of protein isolates from mung bean, black bean and bambara groundnut. J Sci Food Agric 2013, 93:2429-2436.

15. Mubarak A: Nutritional composition and antinutritional factors of mung bean seeds (phaseolus aureus) as affected by some home traditional processes. Food Chem 2005, 89:489-495.

16. Zheng JX: Functional foods-second volume. Beijing: China Light Industry Press; 1999.

17. Lin XXLH, Li WZ: The research of mung bean SOD oral liquid. Food Sci $1997,18: 25-26$.

18. Kruawan K, Tongyonk L, Kangsadalampai K: Antimutagenic and comutagenic activities of some legume seeds and their seed coats. $J$ Med Plants Res 2012, 6(22):3845-3851.

19. Prokudina E, Havlíček L, Al-Maharik N, Lapčík O, Strnad M, Gruz J: Rapid UPLC-ESI-MS/MS method for the analysis of isoflavonoids and other phenylpropanoids. J Food Comp Anal 2012, 26:36-42.

20. Wang M, Gillaspie A, Morris J, Pittman R, Davis J, Pederson G: Flavonoid content in different legume germplasm seeds quantified by HPLC. Plant Gen Res Charac Util 2008, 6:62-69.

21. Li H, Cao D, Yi J, Cao J, Jiang W: Identification of the flavonoids in mungbean (Phaseolus radiatus $L$ ) soup and their antioxidant activities. Food Chem 2012, 135(4):2942-2946.

22. DongKwan K, SangUk C, JungBong K, YoSup R: Variation of flavonoids contents in plant parts of mungbean. Korean J Crop Sci/Hanguk Jakmul Hakhoe Chi 2008, 53:279-284.

23. Koes RE, Quattrocchio F, Mol JNM: The flavonoid biosynthetic pathway in plants: function and evolution. BioEssays 1994, 16(2):123-132.

24. Estomba D, Ladio A, Lozada M: Medicinal wild plant knowledge and gathering patterns in a mapuche community from North-western Patagonia. J Ethnopharmacol 2006, 103:109-119.

25. Singh HP, Kaur S, Batish DR, Kohli RK: Caffeic acid inhibits in vitro rooting in mung bean [vigna radiata (L.) wilczek] hypocotyls by inducing oxidative stress. Plant Growth Regul 2009, 57:21-30.

26. Sosulski FW, Dabrowski KJ: Composition of free and hydrolyzable phenolic acids in the flours and hulls of ten legume species. J Agric Food Chem 1984, 32:131-133.

27. Sawa T, Nakao M, Akaike T, Ono K, Maeda H: Alkylperoxyl radical-scavenging activity of various flavonoids and other phenolic compounds: implications for the anti-tumor-promoter effect of vegetables. J Agric Food Chem 1999, 47:397-402.

28. Kim DK, Jeong SC, Gorinstein S, Chon SU: Total polyphenols, antioxidant and antiproliferative activities of different extracts in mungbean seeds and sprouts. Plant Foods Hum Nutr 2012, 67:71-75.

29. Bowles DJ: Defense-related proteins in higher plants. Annual RevBiochem 1990, 59(1):873-907.

30. Jom KN, Frank T, Engel KH: A metabolite profiling approach to follow the sprouting process of mung beans (vigna radiata). Metabol 2011, 7:102-117.

31. Kessler A, Baldwin IT: Plant responses to insect herbivory: the emerging molecular analysis. Annu Rev Plant Biol 2002, 53:299-328. 
32. Kataria A, Chauhan B, Punia D: Antinutrients and protein digestibility (in vitro) of mungbean as affected by domestic processing and cooking. Food Chem 1989, 32:9-17.

33. Kavas A, Sedef NEL: Nutritive value of germinated mung beans and lentils. J Consumer Stud Home Econ 1991, 15:357-366.

34. Abdel-Rahman E-SA, El-Fishawy FA, El-Geddawy MA, Kurz T, El-Rify MN: The changes in the lipid composition of mung bean seeds as affected by processing methods. Int J Food Eng 2007, 3(5):1-10.

35. Kirchhoff E: Online-publication of the german food composition table "souci-fachmann-kraut" on the internet. J Food Comp Anal 2002, 15(4):465-472

36. Chau CF, Cheung PK: Effect of various processing methods on antinutrients and in vitro digestibility of protein and starch of two Chinese indigenous legume seeds. J Agric Food Chem 1997, 45(12):4773-4776.

37. Amarowicz R, Żegarska Z, Rafałowski R, Pegg RB, Karamać M, Kosińska A: Antioxidant activity and free radical-scavenging capacity of ethanolic extracts of thyme, oregano, and marjoram. Eur J Lipid Sci Technol 2009, 111(11):1111-1117.

38. Moumita P, Lal B, Mahua G: Comparative studies on physicochemical and biochemical characteristics of scented and non-scented strains of mung beans (vigna radiata) of Indian origin. Legume Res-An Inter J 2010, 33(1):1-9.

39. Lawrence PK, Koundal KR: Plant protease inhibitors in control of phytophagous insects. Electron J Biotechnol 2002, 5(1):5-6.

40. Lorensen E, Prevosto R, Wilson KA: The appearance of new active forms of trypsin inhibitor in germinating mung bean (vigna radiata) seeds. Plant Physiol 1981, 68(1):88-92.

41. Messina MJ: Legumes and soybeans: overview of their nutritional profiles and health effects. Am J Clin Nutr 1999, 70(3):439-450.

42. Zhang JR: Detoxication drug in household. Guangzhou: Guangdong Higher Edu Press; 1988.

43. Wongekalak LSP, Jirasripongpun K, Hongsprabhas P: Potential use of antioxidative mungbean protein hydrolysate as an anti-cancer asiatic acid carrier. Food Res Int 2011, 44(3):812-817.

44. Lai F, Wen Q, Li L, Wu H, Li X: Antioxidant activities of water-soluble polysaccharide extracted from mung bean (Vigna radiata $L$.) hull with ultrasonic assisted treatment. Carbohydr Polym 2010, 81(2):323-329.

45. Lee JH, Jeon JK, Kim SG, Kim SH, Chun T, Imm JY: Comparative analyses of total phenols, flavonoids, saponins and antioxidant activity in yellow soy beans and mung beans. Int J Food Sci Tech 2011, 46:2513-2519.

46. Cao D, Li H, Yi J, Zhang J, Che H, Cao J, Yang L, Zhu C, Jiang W: Antioxidant properties of the mung bean flavonoids on alleviating heat stress. PLoS One 2011, 6(6):e21071.

47. Kim JH, Lee BC, Kim JH, Sim GS, Lee DH, Lee KE, Yun YP, Pyo HB: The isolation and antioxidative effects of vitexin from acer palmatum. Arch Pharm Res 2005, 28(2):195-202.

48. Wang S, Rao P, Ye X: Isolation and biochemical characterization of a novel leguminous defense peptide with antifungal and antiproliferative potency. Appl Microbiol Biotechnol 2009, 82(1):79-86.

49. Wang S, Shao B, Fu H, Rao P: Isolation of a thermostable legume chitinase and study on the antifungal activity. App/ Microbiol Biotechnol 2009, 85(2):313-321.

50. Wang PF, Ye SY, Rao XY: Research progress on the biological activities and functions of mung beans. J Chin Insti Food Sci Tech 2004, 1:26.

51. Ye XY, Ng TB: Mungin, a novel cyclophilin-like antifungal protein from the mung bean. Biochem Biophys Res Commun 2000, 273(3):1111-1115.

52. Wang $S$, Wu J, Rao P, Ng TB, Ye X: A chitinase with antifungal activity from the mung bean. Protein Expr Purif 2005, 40(2):230-236.

53. Lee SJ, Lee $J H$, Lee HH, Lee S, Kim SH, Chun T, Imm JY: Effect of mung bean ethanol extract on pro-inflammtory cytokines in LPS stimulated macrophages. Food Sci Biotechnol 2011, 20(2):519-524.

54. Yeap SK, AliN M, YusofH M, Noorjahan BA, Boon KB, Wan YH, Soo PK, Kamariah $L$ : Antihyperglycemic effects of fermented and nonfermented mung bean extracts on alloxan-induced-diabetic mice. BioMed Res Int 2012, 2012:1-7.

55. Bellik Y, Hammoudi S, Abdellah F, Iguer-Ouada M, Boukraa L: Phytochemicals to prevent inflammation and allergy. Recent Patents on Inflammation \& Allergy Drug Discovery 2012, 6(2):147-158.
56. Cherng J-M, Chiang W, Chiang L-C: Immunomodulatory activities of edible beans and related constituents from soybean. Food Chem 2007, 104(2):613-618.

57. Yao Y, Chen F, Wang M, Wang J, Ren G: Antidiabetic activity of mung bean extracts in diabetic KK-Ay mice. J Agric Food Chem 2008, 56(19):8869-8873.

58. Randhir R, Shetty K: Mung beans processed by solid-state bioconversion improves phenolic content and functionality relevant for diabetes and ulcer management. Innov Food Sci Emerg Tech 2007, 8(2):197-204.

59. Li ZX: Experimental hyperlipidemia and artery effect of mung bean in rabbit. Chin J Cardiol 1981, 3:228-231.

60. Zhang HMH, Cai HS: Discussion on study of lipid-lowering by traditional Chinese medicine. Lishizhen Med Mat Med Res 1995, 6:34-35.

61. Hsu GSW, Lu YF, Chang SH, Hsu SY: Antihypertensive effect of mung bean sprout extracts in spontaneously hypertensive rats. J Food Biochem 2011, 35(1):278-288

62. Matousek J, Podzimek T, Pouckova P, Stehlik J, Skvor J, Soucek J, Matousek J: Antitumor effects and cytotoxicity of recombinant plant nucleases. Oncol Res 2009, 18(4):163-171.

63. Xu B, Chang SK: Comparative study on antiproliferation properties and cellular antioxidant activities of commonly consumed food legumes against nine human cancer cells. Food Chem 2012, 134(3):1287-1296.

64. Zhao YR, Li ZW, Zhao C, Fu R, Wang XH, Li ZY: Effects of recombinant mung bean trypsin inhibitor fragments on migration of colon cancer cell SW480. J Shanxi Univ (Nat Sci Ed) 2012, 1:29

65. Zhu S, Li W, Li JH, Arvin J, Andrew ES, Wang HC: It is not just folklore: the aqueous extract of mung bean coat is protective against sepsis. Evidence-Based Compl Alter Med 2012, 2012:1-10.

66. Lee CH, Yoon SJ, Lee SM: Chlorogenic acid attenuates high mobility group Box 1 (HMGB1) and enhances host defense mechanisms in murine sepsis. Mol Med 2012, 18(1):1437-1448.

doi:10.1186/1752-153X-8-4

Cite this article as: Tang et al:: A review of phytochemistry, metabolite changes, and medicinal uses of the common food mung bean and its sprouts (Vigna radiata). Chemistry Central Journal 2014 8:4.

Publish with ChemistryCentral and every
scientist can read your work free of charge
"Open access provides opportunities to our
colleagues in other parts of the globe, by allowing
anyone to view the content free of charge."
W. Jeffery Hurst, The Hershey Company.
- available free of charge to the entire scientific community
- peer reviewed and published immediately upon acceptance
- cited in PubMed and archived on PubMed Central
- yours - you keep the copyright
submit your manuscript here:
http://www.chemistrycentral.com/manuscript/

